\title{
Finite element based design of a polymer rotor of centrifugal pump
}

\author{
A. Allali*, S. Belbachir**, A. Lousdad*** \\ *Laboratory of applied mechanics, faculty of Mechanical Engineering, University of sciences and technology of Oran \\ (USTO), B.P. 1505, Oran El M'Naouer, 31000, Oran, Algeria, E-mail: ahmedenergetique @ gmail.com \\ **LMPM, Mechanical engineering department, Faculty of technology, University of Sidi Bel Abbes, BP 89 Cité Ben \\ M'hidi, Sidi Bel Abbes, 22000, Algeria, E-mail: belbachirsaida@yahoo.com \\ ***Laboratory mechanics of structure and solids (LMSS), Mechanical engineering department, Faculty of technology, \\ University of Sidi Bel Abbes, 22000 Sidi Bel Abbes, Algeria,Email: a_lousdad@yahoo.com
}

cross $^{\text {ref }}$ http://dx.doi.org/10.5755/j01.mech.22.1.12218

\section{Introduction}

Centrifugal pumps play an important role in many sectors and domains. They exist in the water distribution networks, in agriculture, and mining and petrochemical industries. The objective of their design concerns the optimization of the design steps as well as the fabrication and characterization of centrifugal pump. In this regards the design of these pumps must be improved to fulfill the energetic efficiency, the reliability, performance and reduction of cost of electric consumption and minimizing the losses. The users were confronted to the problematic of design of the centrifugal pump components. In this work, in order to identify and predict the parameters which improve the performance of centrifugal pump made of polymerie material, three cases were analyzed by varying different parameters. The variation of the parameters concerns the width of the blade, the number of blades and the external diameter of the impeller. This is carried out by finite element method (FEM) using ABAQUS software. The aim of this research is the investigation on the displacements in order to avoid wear phenomenon of the material due to the friction between the impeller and the volute. On the other hand, the research investigates the stresses capable of producing the deformation of the polymer. From literature, it has been found that most of the researches works aim to predict the performance of centrifugal pumps with radial volute and the impeller dimensioning. L. Wen-Guang et al [1] are among researches that had contributed by studying the effect of the number of blades on the centrifugal pump performance. Another investigation was carried out on the internal flow in an impeller of a centrifugal pump by Weidong Zhou et al [2]. Moreover, A. Johns [3] is directed toward numerical methods for flow analysis and the impeller design of centrifugal pump. Another experimental and numerical study of an internal flow in an impeller was carried out by Cui Baolinge et al [4]. Recently, M. Shojaee Fard et al [5] were interested in the effect of the number of blades, the exit angle of the blade in a centrifugal pump during the flow of a viscous fluid. E. Bacharoudis et al [6] had developed a parametric study of impeller of a centrifugal pump with changes of exit angle of the blade. A three dimensional experimental and numerical study of viscous fluid flow in a centrifugal pump was proposed and conducted by $\mathrm{M}$. Shojaee Fard et al [7]. Another investigation was conducted on the characteristics of performance in impeller of a pump by M. Gôlcu et al [8]. J. Gonzalez et al [9] had in- troduced in their investigation the dynamic effect of the impeller-volute interaction in a centrifugal pump. A strategy of optimization of design and performance analysis of turbo machinery with incompressible fluid had been proposed by M. Asuaje [10]. The present work concerns a parametric study of an impeller design made of polymer of a centrifugal pump.

\section{Impeller drawing}

\subsection{Methodology of impeller dimensioning}

The main geometrical parameters of the impeller [11] are shown in Fig. 1. There are previously defined and are:

- Height $H$, flow rate $q_{v a}$, rotational speed $N$;

- Blade inlet: $\beta_{10}$ angle, radius to median line $R_{1}$, width $b_{1}$

- Blade outlet: $\beta_{2 \infty}$, angle , outlet radius $R_{2}$, width $b_{2}$;

- Anchor section : radius $R_{o}$.

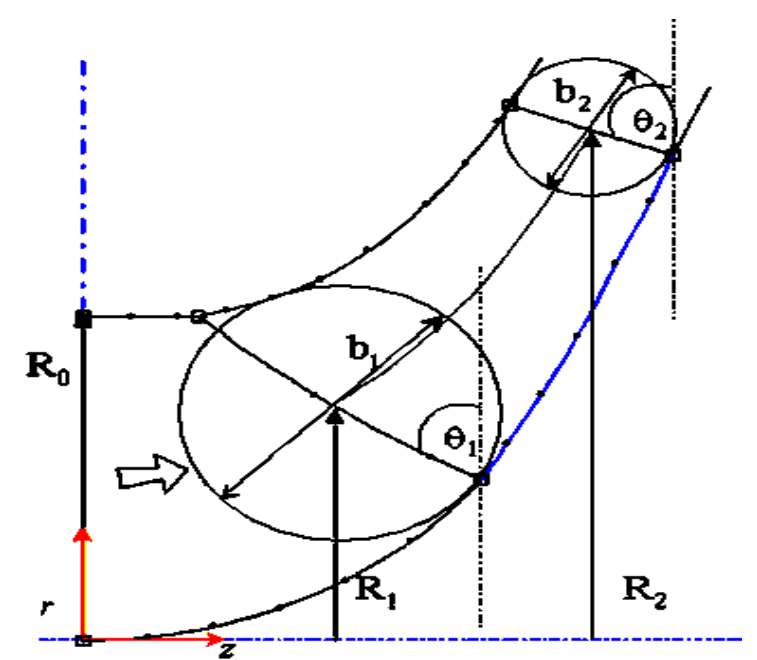

Fig. 1 Geometrical parameters of the impeller

\subsubsection{Calculation of radius $R_{1}$ and width $b_{1}$}

The property of velocities triangle allows writing:

$$
\left\{\begin{array}{l}
\operatorname{tg} \beta_{1}=\frac{U_{1}}{C_{1}} ; \\
U_{1}=\varpi R_{1},
\end{array}\right.
$$


where $U_{1}$ is the driving speed, $C_{1}$ is the absolute velocity.

In the adaptation state, the continuity equation permits to write:

$$
\left\{\begin{array}{l}
\operatorname{tg} \beta_{1}=\operatorname{tg} \beta_{10} \\
C_{1}=\frac{q_{v a}}{S_{1}}
\end{array}\right.
$$

The blade inlet section $S_{1}$ is defined as:

$$
S_{1}=2 \pi R_{1} b_{1}
$$

It has been demonstrated on theoretical basis that the inlet section of pumps with good aspiration capacity, well dimensioned for no cavitations can be determine as follows:

$$
\begin{aligned}
& S_{1}=S_{1 o p t}=\pi R_{o p t}^{2} ; \\
& R_{o p t}=2.25\left(\frac{q_{v a}}{N}\right)^{\frac{1}{3}} .
\end{aligned}
$$

From Eqs. (1), (2) and (4), we can determine the radius of median line of the blade inlet:

$$
R_{1}=\frac{q_{v a} \operatorname{tg} \beta_{10}}{\pi v R_{o p t}^{2}} .
$$

According to Eq. (3) we obtain the width of the blade entrance:

$$
b_{1}=\frac{S_{1}}{2 \pi R_{1}} .
$$

\subsubsection{Calculation of external diameter $R_{2}$}

From Cordier's diagram and for a specific given angular speed $\Omega$, we can define the best adapted specific radius $\Lambda$. The choice of the external radius $R_{2}$ is made from the specific radius as the following:

$$
R_{2}=\frac{\Lambda\left(q_{v}\right)^{\frac{1}{2}}}{(g H)^{\frac{1}{4}}} .
$$

\subsubsection{Choice of the exit angle}

When the fluid enters the impeller without prior rotation, the theoretical height is given by Euler's equation:

$$
\left\{\begin{array}{l}
H_{t h}=\frac{U_{2} C u_{2}}{g} ; \\
H_{t h \infty}=\frac{U_{2} C u_{2 \infty}}{g},
\end{array}\right.
$$

where $\mathrm{Cu}_{2}$ is the gyration component of the absolute speed. According to this relation, the theoretical elevation height of a compression machine (fan, pump and compressor) depends only on the peripheral speed $U_{2}$ and the gyratory component of the absolute velocity $\mathrm{Cu}_{2}$. The ratio between $U_{2}$ and $C u_{2}$ can be selected in wide limit range. It is strongly related to the output angle of the blade $\beta_{2 \infty}$. The pumps for liquids are constructed with blades tilted back and with angle $\beta_{2 \infty}$ between $50^{\circ}$ and $70^{\circ}$ (arbitrarily chosen value).

\subsubsection{Calculation of the width $b_{2}$}

The hydraulic efficiency $\eta_{H}$ of the impeller is determined using Lomakine's empirical formula at the point of maximum efficiency as:

$$
\eta_{H}=1-\frac{0.42}{\left(\log _{10} \text { dred }-0.172\right)^{2}},
$$

with dred $=4250 \sqrt[3]{\frac{q_{v}}{N}}$, where $q_{v}$ is the flow rate, $N$ is rotational speed.

The theoretical height and infinite height are determined as follows:

$$
\left\{\begin{array}{l}
H_{t h}=\frac{H}{\eta_{H}} ; \\
H_{t h \infty}=\frac{H_{t h}}{\mu},
\end{array}\right.
$$

where $H$ is the prescribed height, $\mu$ is sliding factor.

The gyratory component is deduced from $H_{t h \infty}$ using Euler's relation:

$$
C u_{2 \infty}=\frac{g H_{t h \infty}}{U_{2}} .
$$

The triangle of the speeds at the impeller exit allows calculating the speed $\mathrm{Cr}_{2}$ and the width $b_{2}$ :

$$
\begin{aligned}
& C r_{2}=\frac{U_{2}-C u_{2 \infty}}{\operatorname{tg} \beta_{2 \infty}} ; \\
& b_{2}=\frac{q_{v a}}{2 \pi R_{2} C r_{2}} .
\end{aligned}
$$

\section{Investigation configurations}

The elastoplastic behavior of the impeller of polyethylene PE with a different number of blades $(5,6$ and 8 blades) has been investigated for the configurations shown in Fig. 2 In order to see the effect of this parameter on the Von Mises stresses and the distribution of the displacements, each one of these configurations is made of an entity of impellers, blades and impeller covers.

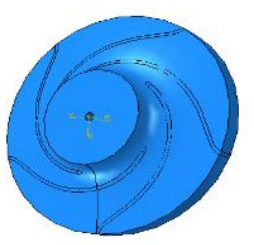

a

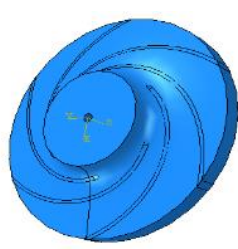

b

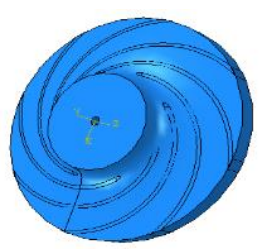

Fig. 2 Investigated configurations: a - Impeller 5 blades; b - Impeller 6 blades; c - Impeller 8 blades 


\section{Elaboration of the pump meshing}

The meshing of the impeller must meet the geometrical and physical criteria. It must also take into account the constraints linked to the study (boundary limits). The mesh is constructed using ABAQUS software. It is the tetrahedral type C3D4 of mesh for the case of the impeller.

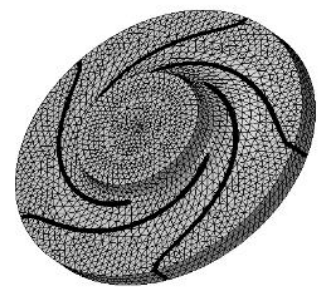

a

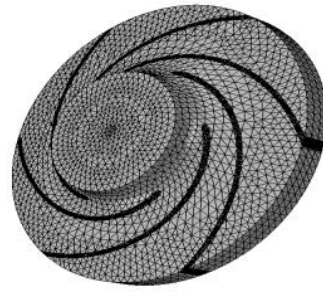

b

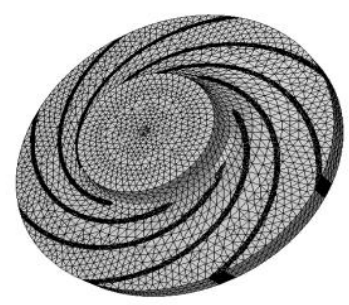

c

Fig. 3 Mesh of the impeller: a-Impeller 5 blades; b - Impeller 6 blades; c - Impeller 8 blades

\section{Conditions of simulation}

By means of software ABAQUS, the conditions of simulation were introduced and are grouped in the following Table:

Conditions of simulation

\begin{tabular}{|c|c|}
\hline Characteristics & ABAQUS \\
\hline Behavior & elastoplastic \\
\hline Simulation I & 5 blades impeller \\
\hline Simulation II & 6 blades impeller \\
\hline Simulation III & 8 blades impeller \\
\hline Impeller meshing & Structured \\
\hline Young's modulus & $127.66 \mathrm{MPa}$ \\
\hline Poisson's ratio & 0.46 \\
\hline Inlet conditions & Fixed (pinned) \\
\hline Impeller internal pressure & $0.3 \mathrm{MPa}$ \\
\hline
\end{tabular}

The loading has been modelised as shown in Fig. 4:
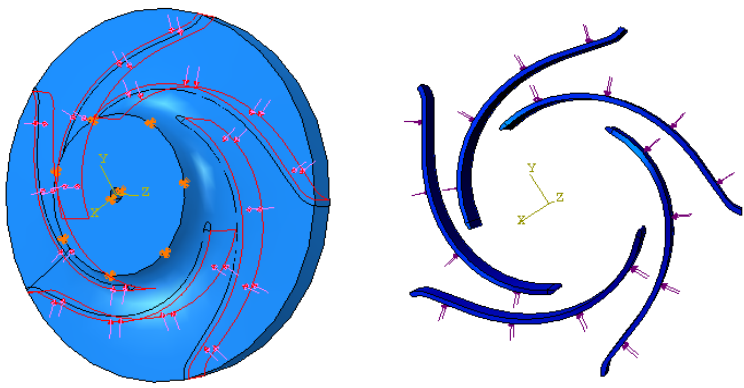

Fig. 4 Load distribution
The data of the elastoplastic response of PE were depicted from the tensile load stress strain curve (Fig.5).

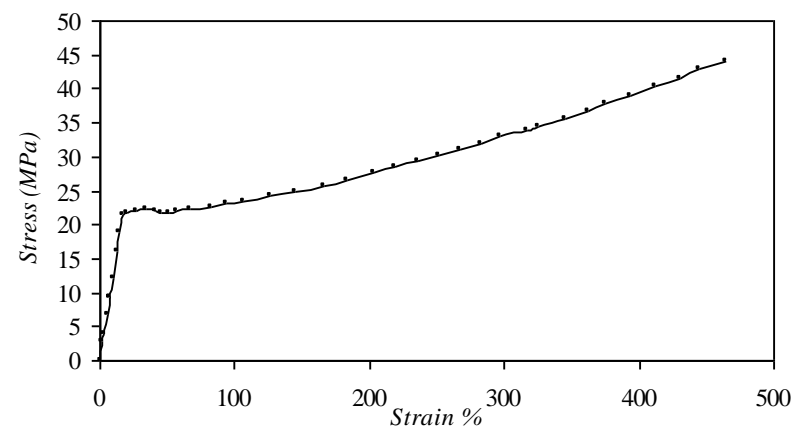

Fig. 5 Stress strain curve

\section{Results and discussion}

The results obtained concerning the evolution of the Von Mises Stresses and the displacements contours have been grouped for a better comparison of each impeller.

\subsection{Effect of variation of the number of blades}

\subsubsection{Evolution of the Von Mises Stresses}

In order to examine the effect of the variation of the number of blades of the impeller on the evolution of the Von Mises stresses and the distribution of the displacements we have considered three cases with 5, 6 and 8 blades respectively while maintaining constant the other parameters of the impeller. The research works in this domain have shown that the lowest performance is obtained with a reduced number of blades. It has been noticed that the difference in pressure between the impeller inlet and the volute outlet increases with increasing number of blades. It comes out that the average velocity at the impeller outlet decreases by increasing the number of blades. This explains the increase of the pressure difference. Fig.6 represents the characteristic curves of Von Mises stresses as a function of distance along path of the impeller. It has been noticed an increase of Von Mises stresses corresponding to the number of blades equals to 8 . However, in the centrifugal pump there will be a considerable increase in torque due to the weight of the impeller which increases with increasing number of blades. This explains the increase of the power and manometric height.

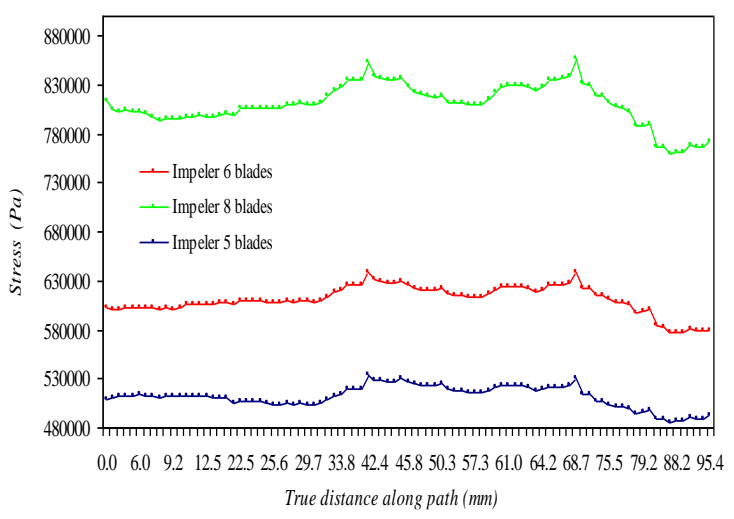

Fig. 6 Stresses versus distance 


\subsubsection{Displacements contours}

The contours of the displacements are illustrated in Fig. 7 in order to show their distribution in the impeller of the centrifugal pump. The displacements due to the pressure loading have been examined while varying the number of blades of the impeller.
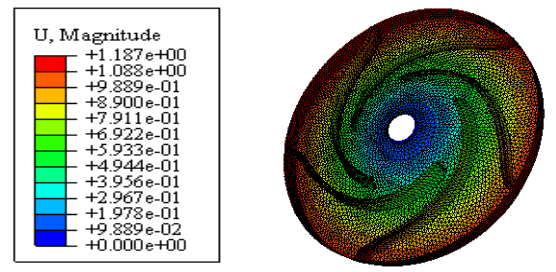

a
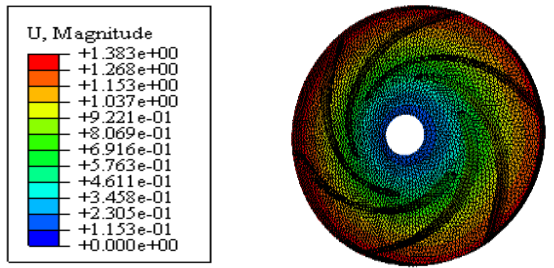

b
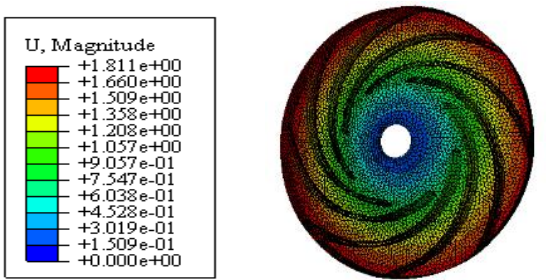

$\mathrm{c}$

Fig. 7 Displacements contours: a - Impeller 5 blades; b - Impeller 6 blades; c - Impeller 8 blades

The values of their displacements are higher at the exit than the rest of the part due to the load distribution and fixed (pinned).

The distribution of displacement contours for the three impellers with different number of blades are perfectly similar. The displacement of the impeller with 8 blades is higher than that of 6 and 5 blades respectively. This provokes a volumic expansion of the impeller under pressure load. Due to this volumic expansion there will be the creation of wear phenomena of material by friction if there is a little clearance between the impeller and the volute. In this case it should be avoided.

\subsection{Effect of the variation of the width of the blade at the impeller outlet}

\subsubsection{Evolution of Von Mises stresses}

For the analysis of the variation of the blade width at the exit of the impeller, the values of 15, 21 and $27 \mathrm{~mm}$ have been selected. The other parameters of the impeller were kept constant. From works carried out in this domain, it has been noticed that the increase of the width of the impeller leads to an increase of the manometric height. This is explained by the expansion of the section which reduces the load loss due to the increase of the flow speed. Also, it has been observed that the power increases with increasing blade width. This is due to the rise of the rotational torque load applied to the shaft of the impeller. It comes out that for a high flow rate, the efficiency decreases by reducing the width of the blade. Moreover, it has realized that the increase in width provokes a decrease in pressure difference between the inlet and outlet of the impeller. From this wok and with reference to Fig.8, it is observed that the more the increase in impeller width, the more the increase in Von Mises stresses between the inlet and outlet of the impeller.

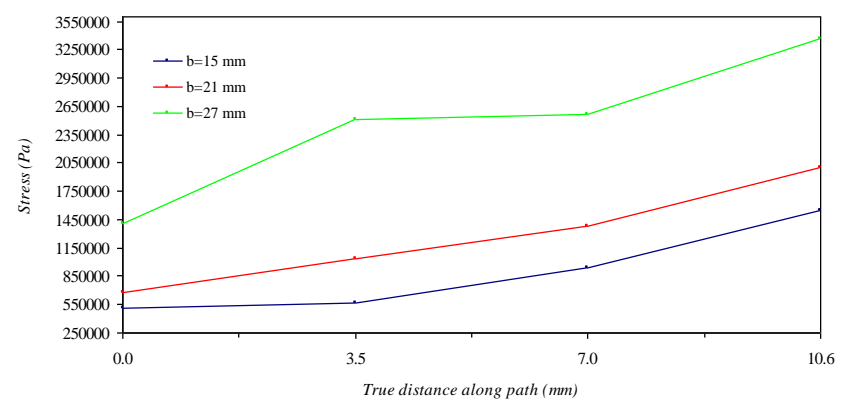

Fig. 8 Von Mises stresses with respect to distance

\subsubsection{Contours of displacements}

The displacement had been examined by changing the width of the impeller respectively from 15, 21 and $27 \mathrm{~mm}$. An increase of displacements has been observed between the input and output of the impeller as shown in Fig. 9. The increase in the width of the impeller makes the values of the displacements higher. This is due to the pressure distribution which is more concentrated at the external end of the blade.
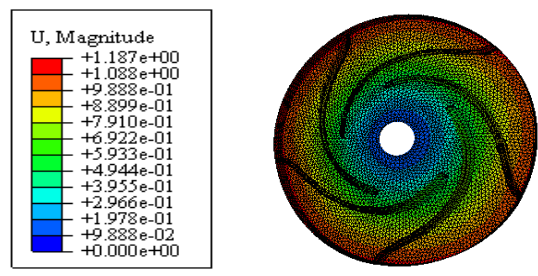

$\mathrm{a}$
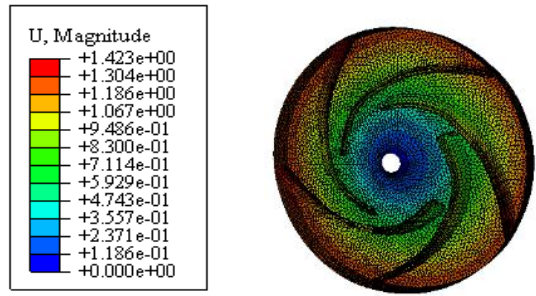

b
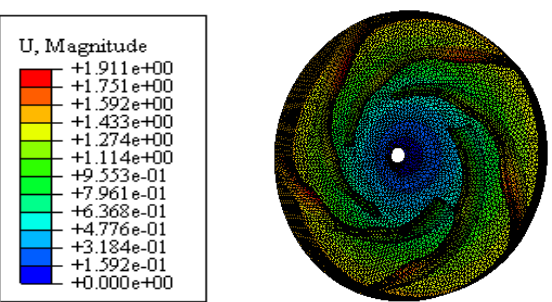

Fig. 9 Contours of displacement: a - width $b_{1}=15 \mathrm{~mm}$; $\mathrm{b}$ - width $b_{2}=21 \mathrm{~mm} ; \mathrm{c}-$ width $b_{3}=27 \mathrm{~mm}$ 
6.3. Effect of the external diameter variation of the impeller

\subsubsection{Evolution of Von Mises stresses}

In order to analyze the effect of the impeller diameter on evolution of Von Mises stresses, three different

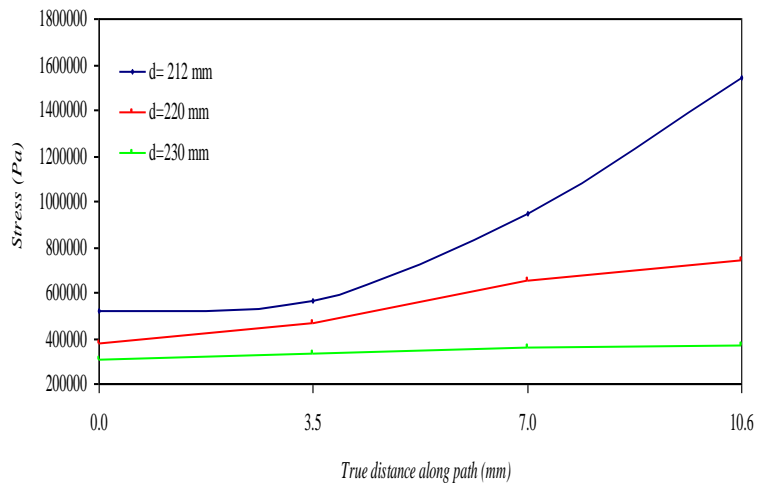

Fig. 10 Von Mises stresses with respect to distance
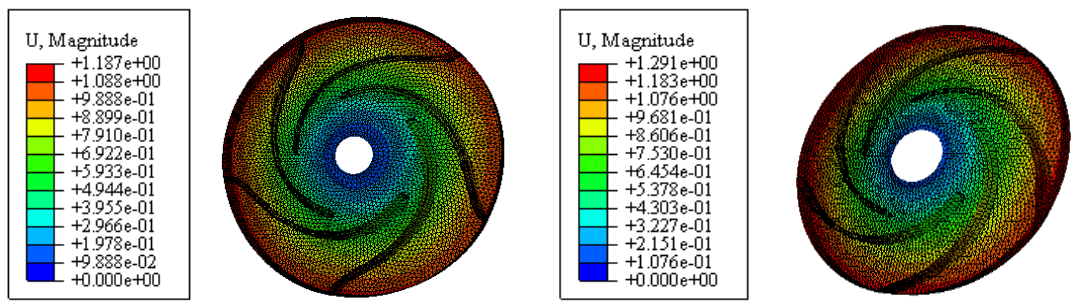
outlet of the impeller. Fig. 11.

diameters have been selected 212, 220 and $230 \mathrm{~mm}$ respectively. According to recent research [10], it has been observed that an increase in the impeller diameter leads to an increase in the manometric height. This is due to the increase of the section of the impeller causing a load loss. On the other hand, there will be a considerable increase of the torque due to the weight of the impeller becoming heavier with the increase of its diameter. This explains the increase in pressure and the decrease in the average speed at the

The present work shows the evolution of Von Mises stresses with respect to distance (diameter). From Fig.10 it is observed that the increase of diameter leads to a decrease of Von Mises stresses.

\subsubsection{Contours of displacements}

The displacements had been examined by changing the external diameter of the impeller respectively from 212, 220 and $230 \mathrm{~mm}$. An increase of the external diameter provokes an increase of the displacement as shown in

Fig. 11 Contours displacements: a - diameter $D_{1}=212 \mathrm{~mm}$; b - diameter $D_{2}=220 \mathrm{~mm}$; c - diameter $D_{3}=230 \mathrm{~mm}$

\section{Conclusion}

In this numerical study, the elastoplastic mechanical behavior of a polymer impeller (PE) has been developed. These materials have a vital interest in a time of environmental policies. They are more useful in the manufacture of centrifugal pumps organs by their good aging and resistance to corrosion. In this context the work has been addressed in order to identify the parameters that improve the performance of a centrifugal pump such as the number $N$, the width $b$ of the blade and the external diameter of the impeller. The geometrical data of the impeller were taken from an existing centrifugal pump and based turbomachine theory. The effects of these parameters on the displacements and Von Mises stresses have been studied and analyzed. The computations were made using finite element method (FEM) within ABAQUS code. The results obtained by numerical simulations show that these parameters have a sensitive effects on the displacements and Von Mises stresses. This has a direct impact on the prevention against the fracture of a polymer impeller. Finally, the results highlight and put into evidence the benefit of the use of numerical approach for a better design, a better characterization and analysis of centrifugal pump.

\section{References}

1. Wen-Guang Li, et al. 2002. Influence of the number of impeller blades on the performance of centrifugal oil pumps, World Pumps 427: 32-35.

http://dx.doi.org/10.1016/S0262-1762(02)80126-2.
2. Weidong Zhou, et al. 2003. Investigation of flow through centrifugal pump impellers using computational fluid dynamics, Intern. Journal of Rotating Machinery 9(1): 49-61. http://dx.doi.org/10.1155/S1023621X0300006X.

3. Anagnostopoulos, J.S. 2009. A fast numerical method for flow analysis and blade design in centrifugal pump impellers, Computers \& Fluids 38(2): 284-289. http://dx.doi.org/10.1016/j.compfluid.2008.02.010.

4. Cui Baoling, et al. 2006. The flow simulation and experimental study of low-specific-speed high-speed complex centrifugal Impellers, Chinese J. Chern. Eng. 14(4): 435-441. http://dx.doi.org/10.1016/S1004-9541(06)60096-7.

5. Shojaee Fard, M.H.; Boyaghchi, F.A. 2007. Studies on the influence of various blade outlet angles in a centrifugal pump when handling viscous fluids, American Journal of Applied Sciences 4(9): 718-724. http://dx.doi.org/10.3844/ajassp.2007.718.

6. Bacharoudis, E.C.; et al. 2008. Parametric study of a centrifugal pump impeller by varying the outlet blade angle, The Open Mechanical Engineering Journal 2: $75-83$. http://dx.doi.org/10.2174/1874155X00802010075.

7. ShojaeeFard, M.H.; et al. 2006. Experimental study and three-dimensional numerical flow simulation in a centrifugal pump when handling viscous fluids, IUST International Journal of Engineering Science 17(34): 53-60.

8. Gôlcü, M.; Paucar, Y. 2005. Investigation of performance characteristics in a pump impeller with low 
blade discharge angle, World Pumps 468: 32-40. http://dx.doi.org/10.1016/S0262-1762(05)70749-5.

9. Gonzalez, J.; et al. 2002. Numerical simulation of the dynamic effects due to impeller-volute interaction in a centrifugal pump, Transactions of the ASME Journal of Fluids Engineering 124(2): 348-35. http://dx.doi.org/10.1115/1.1457452.

10. Miguel Asuaje 2003. Methodology and optimisation in the design and analysis of turbo machinery performance with incompressible fluid, Doctorate thesis: ENSAM-Paris.

11. Robert Rey; Farid Bakir 2008. Helicon-centrifugal and centrifugal Machines, T. III.

A. Allali, S. Belbachir, A. Lousdad

FINITE ELEMENT BASED DESIGN OF A POLYMER ROTOR OF CENTRIFUGAL PUMP

S u m m a r y

Polymeric pumps represent a technological solution when used for aggressive chemical liquids and abrasives. The present work investigates the effect of pressure load on the elastoplastic behavior of an impeller made of polymer. The main objective is a comparison between impellers with different parameters such as number of blades, external diameter and width of the blade. The computations are made using three-dimensional finite element under ABAQUS code. The behavior of the polymeric impeller is investigated under mechanical loads taking into consideration the mechanical characteristics of the material. This tark is conditioned by a deep understanding of the elastoplastic behavior of the polymeric impeller. The results obtained show the parameters under consideration have a sensitive effects on the behavior of the impeller concerning the displacements and Von Mises stresses. The present work as well as the other research mentioned in this paper aim for a better design and optimization to meet a good performance of centrifugal pump.

Keywords: Design, Centrifugal pump, Impeller, Elastoplastic, polymer, displacement, Stress, Finite Element Method, ABAQUS.

Received May 07, 2015

Accepted January 06, 2016 